\title{
Identifying cost-saving opportunities for surgical care via multicenter time-driven activity-based costing (TDABC) analysis as exemplarily shown for cholecystectomy
}

\author{
Ana Paula Beck da Silva Etges ${ }^{1}$, Luciane Nascimento Cruz $^{2} \wedge$, Rosane Paixão Schlatter ${ }^{3}$, \\ Jeruza Neyeloff ${ }^{3} \wedge$, Eliziane Ferranti ${ }^{4} \wedge$, Luciane Kopittke ${ }^{5} \wedge$, Altacilio Aparecido Nunes ${ }^{6} \wedge$, José Sebastião \\ dos Santos $^{6} \wedge$, Andrea Queiroz Ungari ${ }^{6} \wedge$, José Albuquerque de Figueiredo Neto ${ }^{7}$, José Luiz Nogueira ${ }^{8}$, \\ Renata Melo de Assis ${ }^{7}$, Leila Beltrami Moreira ${ }^{9}$, Carisi Anne Polanczyk ${ }^{10} \wedge$
}

${ }^{1}$ National Institute of Science and Technology for Health Technology Assessment (IATS), CNPq/Brazil (project: 465518/2014-1), Epidemiology Program, School of Medicine, UFRGS, Porto Alegre, RS, Brazil. School of Technology, Pontifícia Universidade Católica do Rio Grande do Sul, Porto Alegre, RS, Brazil; ${ }^{2}$ National Institute of Science and Technology for Health Technology Assessment (IATS), CNPq/Brazil (project: 465518/2014-1), Hospital Moinhos de Vento (HMV), Porto Alegre, RS, Brazil; ${ }^{3}$ National Institute of Science and Technology for Health Technology Assessment (IATS), CNPq/Brazil (project: 465518/2014-1), Hospital de Clínicas de Porto Alegre, Porto Alegre, RS, Brazil; ${ }^{4}$ Hospital de Clínicas de Porto Alegre, Porto Alegre, Rio Grande do Sul, Brazil; ${ }^{5}$ Hospital Nossa Senhora da Conceição, Porto Alegre, RS, Brazil; ${ }^{6}$ University of São Paulo (FMRP-USP), Hospital das Clínicas, School of Medicine Ribeirão Preto, Ribeirão Preto, SP, Brazil; ${ }^{7}$ Federal University of Maranhão (UFMA), Hospital Universitário Presidente Dutra, São Luís, MA, Brazil; ${ }^{8}$ Federal University of Mingas Gerais (HC-UFMG), Hospital das Clínicas, Belo Horizonte, MG, Brazil; ${ }^{9}$ Hospital de Clínicas de Porto Alegre, Health Technology Assessment Division (NATS), Porto Alegre, RS, Brazil; ${ }^{10}$ National Institute of Science and Technology for Health Technology Assessment (IATS), CNPq/Brazil (project: 465518/2014-1), Graduate Cardiology Program, School of Medicine, Federal University of Rio Grande do Sul, Porto Alegre, RS, Brazil, Hospital Moihos de Vento, Porto Alegre, RS, Brazil

Contributions: (I) Conception and design: APBDS Etges, LN Cruz, RP Schlatter, J Neyeloff, CA Polanczyk; (II) Administrative support: APBDS Etges, LN Cruz, RP Schlatter, J Neyeloff, CA Polanczyk, E Ferranti; (III) Provision of study materials or patients: L Kopittke, AA Nunes, JSD Santos, AQ Ungari, JA de Figueiredo Neto, J Neyeloff, RM de Assis, LB Moreira; (IV) Collection and assembly of data: APBDS Etges, LN Cruz, RP Schlatter, JN, L Kopittke, AA Nunes, JSD Santos, AQ Ungari, JA de Figueiredo Neto, J Neyeloff, RM de Assis, LB Moreira, CA Polanczyk, E Ferranti; (V) Date analysis and interpretation: APBDS Etges, LN Cruz, RP Schlatter, J Neyeloff, CA Polanczyk, E Ferranti; (VI) Manuscript writing: all authors: All authors; (VII) Final approval of manuscript: All authors.

Correspondence to: Carisi Anne Polanczyk. Ramiro Barcelos, 2350, building 21- 507, 90035-903 - Porto Alegre, RS, Brazil.

Email: cpolanczyk@hcpa.edu.br.

Background: This study applied time-driven activity-based costing (TDABC) to accurately assess costs and to demonstrate how it is possible to estimate cost-saving opportunities by exploring the results achieved with the method.

Methods: This is a cohort retrospective and multicenter cost analysis research, which included data from video-assisted cholecystectomy patients from five public-funded hospitals. The TDABC was applied according to recommendations in the literature for data collection and analyses. Descriptive cost analysis was followed by an estimate of the labor cost that could be saved by redesigning the surgical pathway based on the benchmark care cycle identified in the hospitals studied.

Results: The mean cost per patient was Int\$701.61 and median cost was Int\$679 (IQR, Int\$470-\$821), with physician expenditure being the most representative cost variable (35\%). The cost-saving analysis suggested that the greatest opportunity for savings was physician time consumed during the surgery: Int\$126

^ ORCID: Ana Paula Beck da Silva Etges, 0000-0002-6411-3480; Luciane Nascimento Cruz, 0000-0003-3749-7236; Rosane Paixão Schlatter, 0000-0003-0998-4096; Jeruza Neyeloff, 0000-0002-4413-0494; Eliziane Ferranti, 0000-0002-3467-6135; Luciane Kopittke, 00000002-6606-7756; Altacilio Nunes, 0000-0001-9934-920X; José Sebastião dos Santos, 0000-0001-5118-0361; Andréa Q Ungari, 0000-00018796-5603; José Luiz Nogueira, 0000-0001-7089-073X; Carisi Anne Polanczyk, 0000-0002-2447-2577. 
per patient could be saved by optimizing the physician's involvement in the surgery. When the total labor costs were evaluated, the optimal surgical process estimated for each hospital could save from Int\$18 to Int\$321 per patient (at the most and least efficient of the hospitals, respectively).

Conclusions: By the application of the TDABC, it was demonstrated that the actual care practices to deliver this service varied between the hospitals, resulting in different times and costs for each hospital. These findings suggest that the TDABC method can be used by health managers to redesign surgical pathways, better assess costs and estimate potential cost-saving opportunities to promote value-based strategies in healthcare.

Keywords: Micro-costing; time-driven activity-based costing (TDABC); value-based healthcare; redesign; surgical pathways

Received: 02 May 2021; Accepted: 30 July 2021; Published: 25 June 2022.

doi: $10.21037 /$ jhmhp-21-34

View this article at: https://dx.doi.org/10.21037/jhmhp-21-34

\section{Introduction}

Healthcare expenditures have been increasing worldwide without necessarily delivering better healthcare services $(1,2)$. The continuous search for ways to minimize waste in healthcare is one of the main pillars of value-based initiatives around the globe (3). Value is defined by the achieved patient reported outcomes per costs spent to deliver those outcomes (4). For a healthcare system to successfully migrate from fee for service to value based reimbursement requires advances in cost accounting methods, which can provide more accurate data and identify opportunities to make care pathways more efficient (5).

Costs are generated by performing patient care activities, and cost-savings arises from performing particular activities efficiently, allowing to better apply scarce resources to deliver better healthcare service to the population (6). For competitive healthcare value, patient needs must be met without increasing costs, and transparency about outcomes and costs is necessary to engage providers in a culture of value (6). Learning from best practices can reveal how much time and money can be saved and can guide healthcare delivery redesign initiatives. It can incentivize continuous improvement for the healthcare system, making it more homogeneous between centers (7).

Time-driven activity based costing (TDABC) estimates the costs of a given clinical service by combining information about the patient care pathway with the unit cost of each resource used to provide care (8). The TDABC method was proposed as an improvement to activitybased costing since it makes accurate cost analyses easier to update by estimating two parameters: (I) the unit cost of resource inputs and (II) the time and quantity of resources required to perform a transaction or activity (9). When well-designed, the application of TDABC can optimize resource management on a per-patient basis throughout the entire episode of care (10), helping identify cost-saving opportunities by making healthcare procedures more efficient, competitive, and, consequently, less expensive (11). This method was recently suggested as the gold standard of cost analysis in value-based healthcare initiatives (12).

The application of TDABC to surgical episodes of care has resulted in increased organizational efficiency, including: optimization of operating room scheduling (13); redesigning activities during surgery (14); identifying benchmarks of care when applied across multiple centers (15); reducing cleaning and set up time between surgeries (13); reducing the time between patient arrival and the beginning of surgery, and reducing time spent in the post-anesthesia care unit $(5,16)$. These achievements can be magnified by applying the same method across multiple centers to evaluate healthcare costs and identify cycle of care redesign opportunities (17).

Finding innovative design solutions to identify benchmarks of healthcare service delivery can provide health managers with data to support value-oriented decisions (18). Only through systematic comparison of the entire patient trajectory and risk-adjusted outcomes can managers be confident that the care process is the best alternative (18). As a driver of quality improvement, transparency can be more effective than financial incentives (10), and the combined use of pathway redesign and TDABC methods can achieve a deeper engagement with patients and providers to achieve 
more effective and patient-centered pathways.

Considering a public health system, a method that allows managers to compare surgical pathways and identify benchmarks of costs and healthcare service delivery could serve as a guide to cost saving opportunities. This study applied the TDABC method to accurately assess costs and to demonstrate how it is possible to estimate cost-saving opportunities by exploring the results achieved with the method.

\section{Methods}

The surgical procedure of video-assisted cholecystectomy was selected to exemplify the TDABC application in a multicenter study. The selection of this condition considered that it is performed in volume in all hospitals, and it was expected do not encounter a high variability between the centers. Video-assisted cholecystectomy data were collected retrospectively and simultaneously from five publicly-funded academic hospitals, which are national centers of excellence (A, B, C, D, and E) located in four different states in Brazil. The participating centers were selected based on their expertise in health technology assessment projects, on whether they were members of the Brazilian Network for Health Technology Assessment (REBRATS), and on their availability and personal capabilities in terms of human resources. The characteristics of the hospitals are described in Table S1.

The study was conducted in accordance with the Declaration of Helsinki (as revised in 2013). The study was based on a perspective of the public hospitals that provide healthcare service to the public system and was approved by the ethical committee from the Hospital de Clínicas de Porto Alegre, project number CAAE: 71078617010015327. Approval was granted by all ethical committees of participating hospitals and informed consent was not required because we are not collecting or evaluating personal and individual information from patients or professionals.

\section{Data collection}

Patients who underwent the video-assisted cholecystectomy between March and October 2018 were included in the study at a maximum of 20 consecutively patients per center. Patients were eligible if they had elective video-assisted cholecystectomy during this period and their billing was approved by the Brazilian Unified Health System (SUS).
All centers received instructions on data collection, and a database was created using REDCap web-based software (Vanderbilt University, Nashville, TN, USA). A multidisciplinary team of researchers was responsible for data collection, developing the methodological framework and analyzing the results.

The team that applied the TDABC method consisted of physicians, industrial engineers and professionals with business backgrounds. All suggested methodological steps were strictly followed (Figure S1) $(19,20)$ and the checklist suggested in the literature to report TDABC studies was used to guide the article consolidation (Table S2) (21). By applying TDABC, it was possible to measure the costs of all the resources used to treat a patient's over a complete cycle of care.

Process maps were developed by direct observation of a selected center over a one-week period, followed by validation at the remaining centers. The resulting map was used to identify all resources consumed during the surgery and in each macro-phase procedure: pre-surgery, surgery, and post-anesthesia care unit. The following resource variables were selected for evaluation: personnel, corporate and divisional allocations (structure), and medications and materials related to each phase (pre-procedure, procedure, and post-procedure). A total of 14 surgical pathway cost variables were found (Figure S2), in addition to materials and medications.

Data collection techniques included medical record reviews, direct observation by the researchers, and interviews with the involved personnel (11). For the time data, units of time were collected from patient's medical records and by the procedure observation by a researcher. In each center, all the patients included have their time registers obtained by a researcher that was observing the activities that each patient was being submitted. Then, the length of time that patients spent in each activity and the respective labor and structural resources consumed in each activity was registered in the database for each patient. In addition, the professionals were asked to report the additional time dedicated to surgical prepare activities, and their answers were computed together with the observed time per patient. The quantity and price of materials, prostheses and medications were collected from invoices and documents containing the acquisition costs of supplies, excluding profit margins.

For calculating the structural and labor capacity cost rates (CCR), different strategies were implemented. Fixed hospital costs, such as energy, third party contracts, 
depreciation, system licenses, taxes and general materials used for each patient were estimated per department. Salaries per professional class were considered as labor costs. Indirect departmental costs and overhead, such as administrative costs were not included in this analysis, making the cost information generated a reflex of the direct costs. The not consideration of overhead costs was necessary because of the high variability in level of financial information accessibility in each center.

All financial information was based on the average expenditure incurred per month over a 12 -month period. To calculate the labor capacity cost rates (CCR) for each resource, actual capacity was calculated, given the characteristics of each department. For inpatient areas, where workload is proportional to physical space, the number of beds was included in the calculation. For the professionals, monthly work hours and expected fringe benefit rates were considered. The department's capacity was based on hospital productivity reports and employee allocation scales and complemented by interviews with each department's manager.

\section{Statistical analysis}

The data were consolidated in a Microsoft ${ }^{\circledR}$ Excel spreadsheet and exported to IBM SPSS ${ }^{\circledR}$ for analysis. The analyses were fragmented in descriptive cost analysis and cost saving estimates by identifying benchmarks of patient care for video-assisted cholecystectomy. Cost data were collected in local currency (2019 BRL) and converted to international dollars according to the 2018 purchasing power parity value (22).

Time and cost databases were created for each variable under analysis. The mean, standard deviation (SD) and standard error (SE) of the patient-level cost per site, followed by the composite cost per site were reported descriptively. The median time and cost per phase were then compared, which allowed connections to be the identified between time and cost during the surgical pathway. The TDABC equation, which involves the sum-product of the CCR of each resource and the time consumed by each resource, was applied to the 14 surgical process variables, allowing calculation of the median cost per surgical phase, resource and hospital. The CCR of each resource in the sample of hospitals and the differences in time consumed per resource were used to explain the variation in surgery time and costs.

The analyses were performed to identify the best surgical pathway and potential cost-saving opportunities in each hospital. First, cost composition was measured by determining the median cost of each resource, broken down into labor and non-labor costs for each phase. By identifying the most representative cost variable, cost-saving opportunities were analyzed graphically, specifically surgical times and CCRs with in each hospital.

To explore the most efficient process, the minimum mean time for each labor resource in the surgical pathway was identified among the hospitals, which resulted in the minimum mean time per labor resource. An optimal surgical-process reference was suggested for each hospital (A', B', C', D', and E'), which multiplied the minimum time for each labor resource by the specific CCR resource. The current labor cost was compared to the optimal potential labor cost, and differences between hospitals represent labor cost-saving opportunities that could be achieved by improving the surgical pathway in each hospital.

\section{Results}

During the study period, 100 patients who underwent elective video-assisted cholecystectomy were included (20 patients per hospital). The mean and median costs per patient were Int\$701 and Int\$679, respectively (IQR, Int\$470-\$821). The physician cost was the resource with the highest cost proportion, in average it represented $35 \%$ of the cost per patient. Table 1 shows the costs stratified by hospital.

The median time and CCR for each resource in each phase of the care pathway are shown in Table 2. For all the resources, the CCR differed between hospitals, which indicates that even though some hospitals had a most effective care process, its final cost could have been higher than less efficient hospitals. The median cost per patient per hospital, calculated as the sum of median time and CCR for each variable plus medical supplies, is presented in Table 3. The highest costs were concentrated during the surgery (Table 3), and the greatest variation was in length of time spent in the recovery room after surgery (Table 2).

The median cost per patient per hospital varied between Int\$318 (hospital D) and Int\$764 (hospital E). However, the length of time from pre-procedure to post-surgery was similar between these two hospitals ( $D=3.6$ hours; $\mathrm{E}=3.9$ hours).

\section{Labor cost-saving analysis}

Breaking down the surgery into macro-activities allowed 
Table 1 Cost results for video cholecystectomy in all hospitals

\begin{tabular}{|c|c|c|c|c|c|}
\hline Cost measures/items & \multicolumn{5}{|c|}{ Hospitals } \\
\hline Total cost $(\$)$ & 15,637 & 14,581 & 12,393 & 7,410 & 20,032 \\
\hline Mean (\$) & 782 & 729 & 619 & 375 & 1,001 \\
\hline SD & 190 & 134 & 299 & 145 & 496 \\
\hline Minimum & 523 & 381 & 312 & 201 & 549 \\
\hline Maximum & 1,215 & 984 & 1,578 & 766 & 2,484 \\
\hline \multicolumn{6}{|l|}{ Resource componentes } \\
\hline Assistants* & $\$ 77$ & $\$ 54$ & $\$ 69$ & $\$ 30$ & $\$ 50$ \\
\hline Physicians* & $\$ 259$ & $\$ 218$ & $\$ 246$ & $\$ 144$ & $\$ 335$ \\
\hline Fellow physicians* & $\$ 26$ & $\$ 31$ & $\$ 34$ & $\$ 33$ & $\$ 42$ \\
\hline Structural ${ }^{*}$ & $\$ 176$ & $\$ 138$ & $\$ 85$ & $\$ 116$ & $\$ 439$ \\
\hline Materials and medication & $\$ 144$ & $\$ 234$ & $\$ 38$ & $\$ 34$ & $\$ 28$ \\
\hline
\end{tabular}

*, the cost information indicates the cost per hour of each resource; SD, standard deviation; SE, standard error.

assessment of the way resources are consumed along the entire surgical pathway. Figure 1 compares the cost concentration per labor and non-labor resource in each activity of the surgical pathway in each hospital (excluding medical supplies and drugs). This figure demonstrates the impact of the structural CCR of the surgical room, especially in hospital E. The importance of labor cost during surgery is also notable: physicians represented $66 \%$, on average, of the labor costs during the surgery phase. Thus, data on physician labor time and cost during surgery were used to explore cost-saving opportunities, comparing the most (D) and least (E) efficient hospitals (Table 2). Figure 2 shows that hospital E could save Int $\$ 126$ by reducing physician time in the surgery phase by conforming to hospital D's parameters.

By identifying the potential economic impact of timesaving opportunities for each labor resource, the cost of a redesigned surgical pathway for each hospital was estimated. Figure 3 presents the actual mean labor cost per surgical phase and the optimal labor cost estimated for each hospital. The difference between the actual cost and the optimal estimated cost represents the labor cost-saving opportunity per hospital. Hospital E presented the highest cost-saving opportunity (Int\$321), part of which can explained by time consumed by physicians during surgery. Hospital D had the lowest target labor cost (Int\$207), mostly due to having the lowest physician CCR.

\section{Discussion}

This study generated an accurate direct cost information for video-assisted cholecystectomy in Brazil and showed how the TDABC can contribute to guide redesign initiatives aimed at decreasing healthcare waste in surgical pathways.

TDABC is an important method for identifying opportunities to optimize surgical procedures and has been an emerging topic in the health economics literature $(15,23,24)$. It is frequently associated with discussion about migrating from a fee-for-service to a value-based or bundled reimbursement system (25-27). It has been reported that the fee-for-service payment system create barriers to improving the quality of services delivered to patients and to reducing waste. One of these barriers is that the fee-for-service system does not actually value activities that are essential for the delivery of safe and effective health services (1). The present study concentrated on the main phases of a surgical cycle and found that the amount of time consumed by professionals varied according to hospital, 
Table 2 Cost capacity rate and median time consumed per resource in each phase

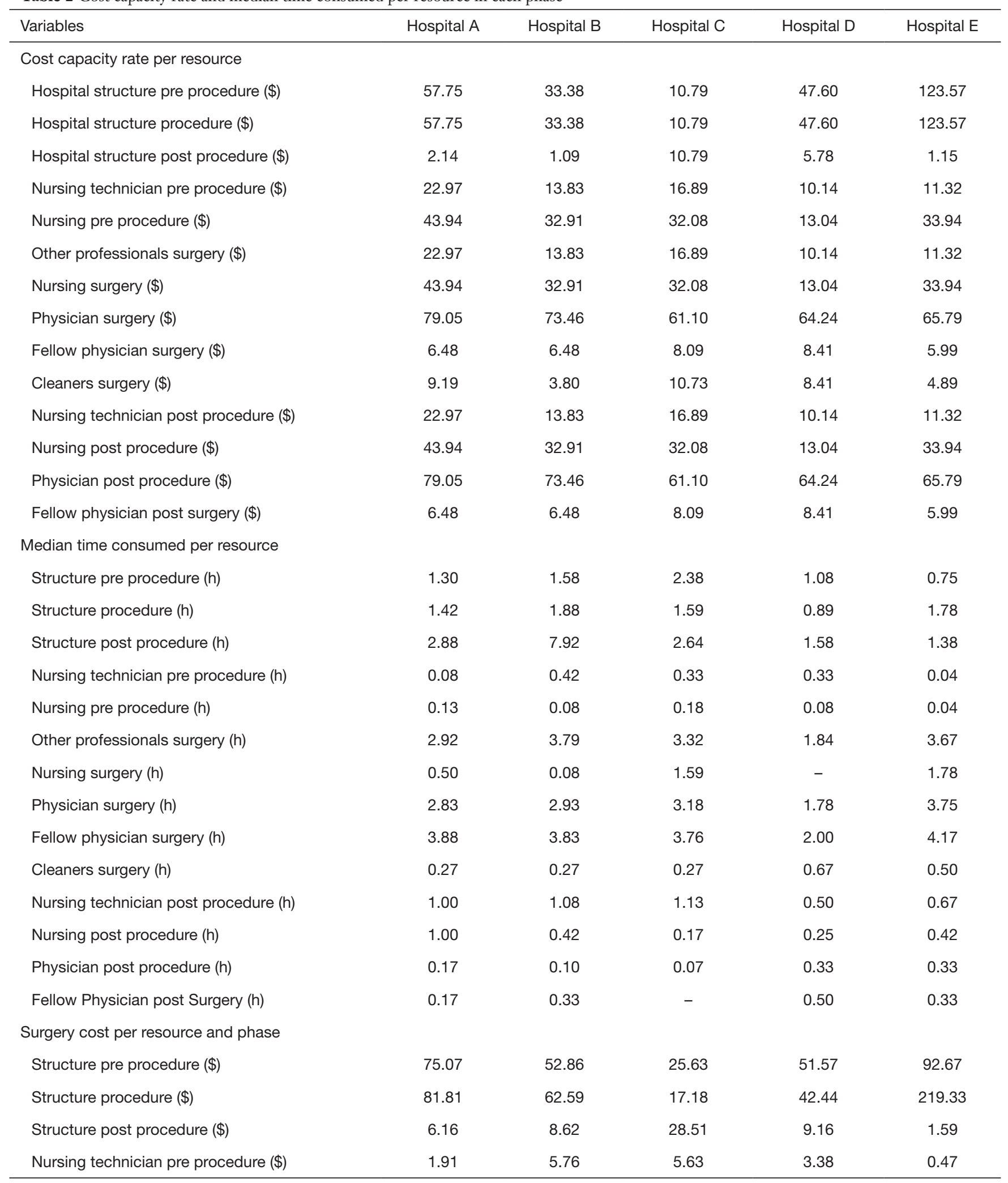

Table 2 (continued) 
Table 2 (continued)

\begin{tabular}{lccccc}
\hline Variables & Hospital A & Hospital B & Hospital C & Hospital D & Hospital E \\
\hline Nursing pre procedure (\$) & 5.86 & 2.74 & 5.88 & 0.98 & 1.41 \\
Other professionals surgery (\$) & 66.98 & 52.44 & 56.01 & 18.67 & 41.52 \\
Nursing surgery (\$) & 21.97 & 2.74 & 51.06 & - & 60.24 \\
Physician surgery (\$) & 223.97 & 215.49 & 194.51 & 114.56 & 246.71 \\
Fellow physician surgery (\$) & 25.09 & 24.82 & 30.40 & 16.83 & 24.96 \\
Cleaners surgery (\$) & 2.45 & 1.01 & 2.86 & 5.61 & 2.45 \\
Nursing technician post procedure (\$) & 22.97 & 14.98 & 19.14 & 5.07 & 7.55 \\
Nursing post procedure (\$) & 43.94 & 13.71 & 5.35 & 3.26 & 14.14 \\
Physician post procedure (\$) & 13.17 & 7.35 & 4.07 & 21.41 & 21.93 \\
Fellow physician post surgery (\$) & 1.08 & 2.16 & - & 4.21 & 2.00 \\
\hline
\end{tabular}

Table 3 Median cost estimate per patient and hospital

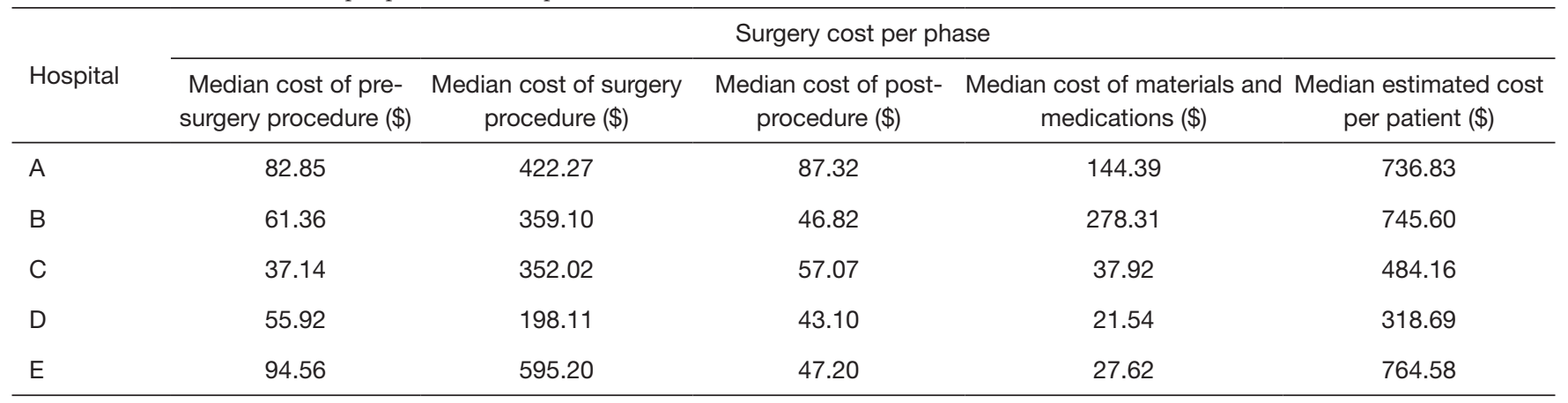

although all of them receive the same public reimbursement based on a fee-for-service system. The full comprehension of the entire care cycle, which can be achieved through the TDABC method, is essential to facilitate patient-centered redesign initiatives and a migration from service to value in the reimbursement system.

The result which demonstrates that part of the differences in costs are explained by the variability on CCR between hospitals, and by the way that resources are consumed by patients throughout the surgical care cycle, highlights how it is valuable to define standards of processes of care to guide surgical procedures in a public health system. It also points out how it is important better understand the costs per hospital, regional and institutional practices before to suggest that one hospital is more or less efficient than other. Although hospital $\mathrm{E}$ did not keep patients in the post-anesthesia care unit for long, it had the highest treatment cost due to the high structural cost of the surgical room and greater physician time during surgery (3.75 hours). On the other hand, hospital B kept patients in the post-anesthesia care unit for a long time but did not have a higher median cost per patient due to its lower structural costs for the surgical room. Hospital D, which had the lowest median cost, completed the surgery quicker than the others and required fewer physician hours to complete the surgery. These differences, which are influenced by organizational culture and regional variations in resource costs, were only identified because of the level of information granularity that the TDABC provides and allows the identification of hospitals which could be assumed as a benchmark to guide cost-saving initiatives.

Porter and Teisberg (6) proposed the concept of valuebased health management to ensure the way organizations that are reimbursed cooperates with improving the quality of healthcare services. Allowing healthcare systems to migrate from volume- to patient-centered systems requires methodological advances that enable understanding of 


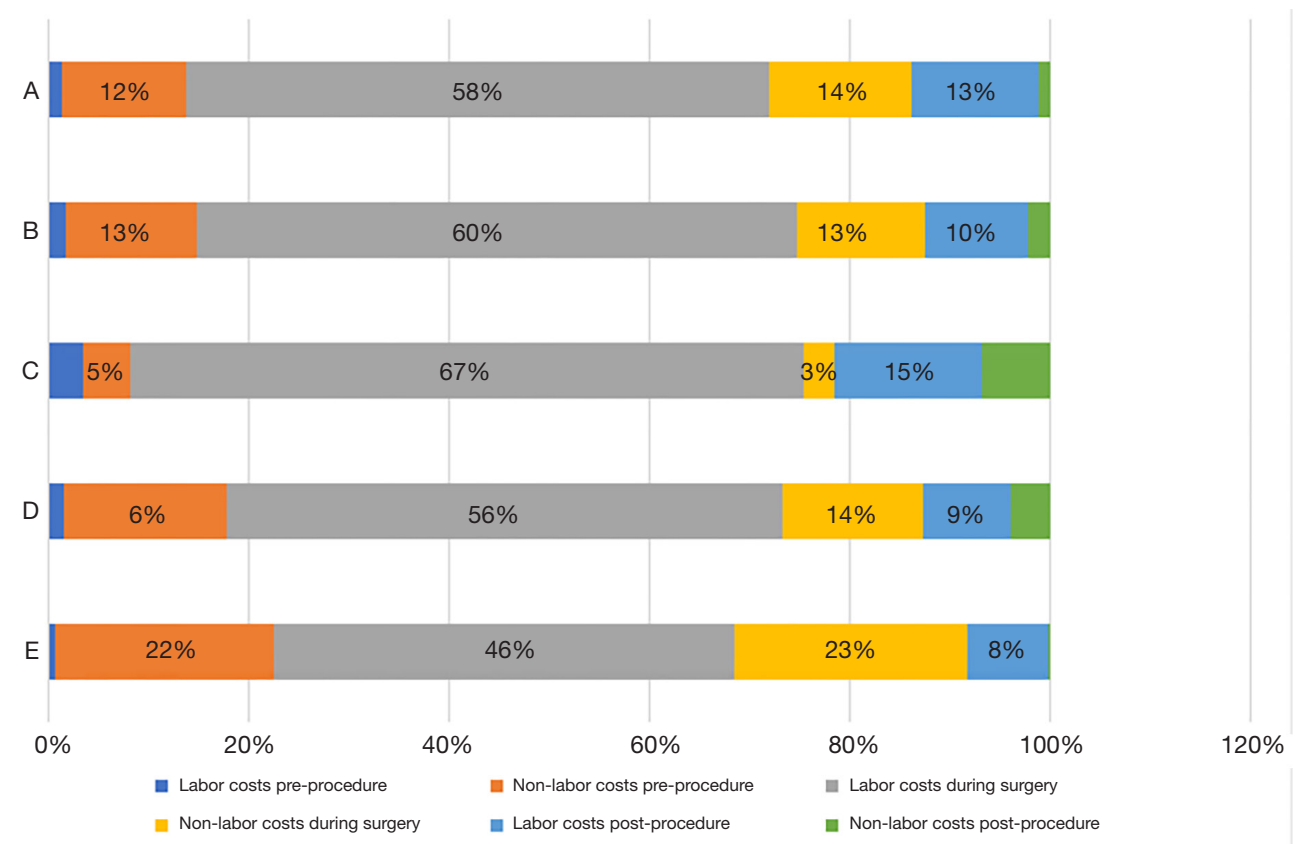

Figure 1 Cost composition per hospital. Labor costs include physicians, nurses, nursing technicians, fellow physicians and cleaners. Nonlabor costs include fixed building costs, such as depreciation, energy, general materials.

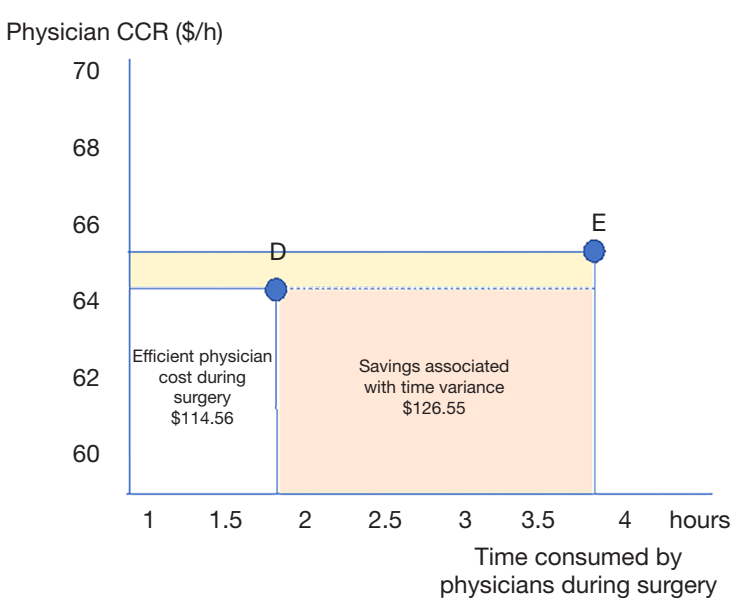

Figure 2 Cost-saving opportunities associated with physician costs during the surgical episode. CCR, cost capacity rate.

patient-specific and individual resource consumption over the course of the care cycle (8).

Motivated by the Enhanced Recovery After Surgery (ERAS) Group recommendations, surgical trajectory redesign efforts have been embraced by health managers (28). Nevertheless, only a few detailed studies have reported on the economic impact of these recommendations. In a systematic review of cost-effectiveness studies for ERAS programs, we pointed out that the different methods used to evaluate ERAS costs decrease the accuracy of the data and the possibility of using them in future high-quality scientific studies (29). In another systematic review on the economic impact of ERAS implementation, we demonstrated that standard methods for correctly evaluating ERAS costs must be defined to achieve more effective analyses of ERAS programs (30). Given that the TDABC methodology can lead to better understanding of labor and non-labor resource use in surgical pathways, we suggest that future studies use the TDABC to evaluate the economic impact of best practices defined in the ERAS recommendations, which would allow a complete value assessment, i.e. one that includes clinical, process and financial outcomes (29).

Our results suggested that the TDABC can be used to guide the identification of surgical redesign initiatives that could result in cost-savings and waste reduction in healthcare. In addition, by the level of details in the cost information that is achieved, the TDABC method can collaborate for deeper engagement between patients and providers to achieve more effective and patient-centered pathways. 
Real labor cost compared with optimal labor cost

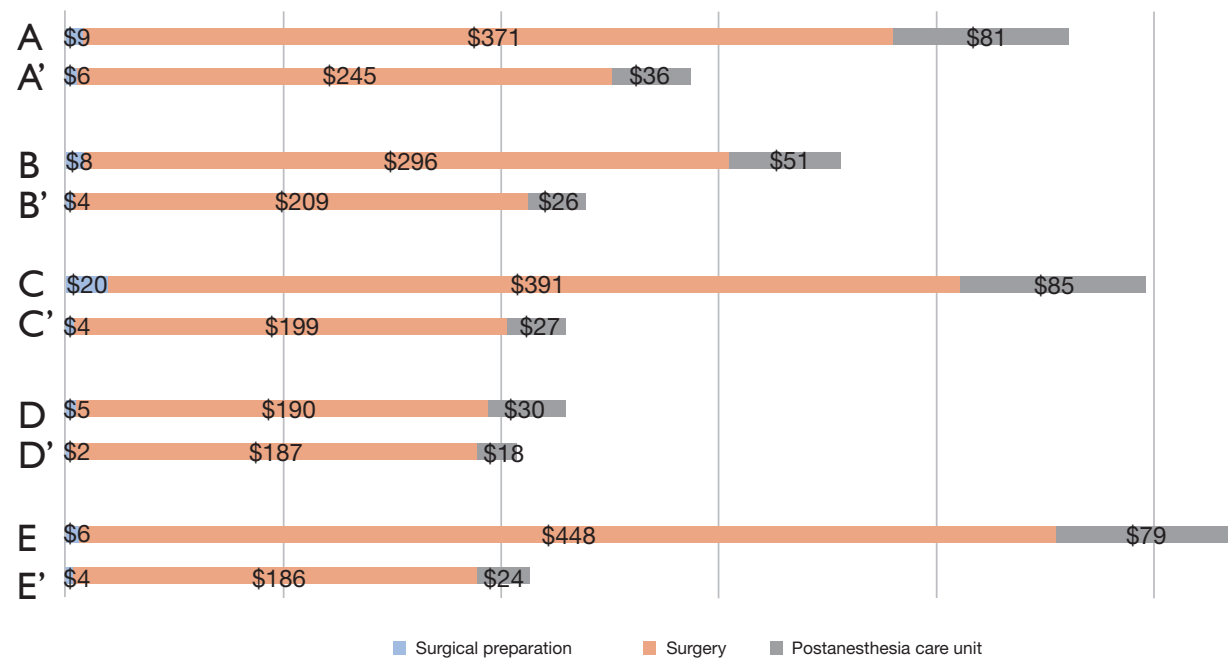

Figure 3 The mean assessed labor cost and the estimated optimal labor cost per hospital. A, B, C, D and E represents the real labor cost calculated for each hospital and A', B', C', D' and E' represents the estimated labor cost for optimal surgical-processes, which are multiplied by the minimum time for each labor resource identified and the specific labor resource cost capacity rate of each hospital.

\section{Limitations}

A few limitations should be considered regarding the present study. First, a single surgical procedure was evaluated, and the replication of this methodology to other surgeries and inpatient services is recommended. Second, the study considered only direct costs and not the quality of the service delivered in each hospital, although all patients were discharged and had no complications. Analysis of health outcomes must be added to cost assessment in future studies to ensure a value management approach.

This study included only hospital direct costs, the hospital overhead costs were excluded because of the differences in the financial information accessibility from each center. This variability, in multicenter studies, was identified as a challenge to apply the TDABC with the same level of quality in all centers.

The analyses presented are estimating potential labor cost savings that could be achieved by implementing a redesign initiative. It is strongly recommended in future studies to apply the TDABC to evaluate the results achieved in a surgical redesign project, following the recommendations available on the literature (31) and including the impact of materials and medications. Finally, reducing the time of the video-assisted cholecystectomy would free up the operating room for other procedures, which would further reduce costs, but this opportunity cost was not investigated.

\section{Conclusions}

This is the first multicenter TDABC study conducted in Latin America that has evaluated a high-volume surgical procedure to estimate cost-saving opportunities in health service delivery. It was possible to demonstrate how the results achieved by the application of the TDABC method can be used to identify benchmarks of care that can guide surgical redesign initiatives. Although it is a well-known procedure, the actual care practices varied significantly, which translates into different times and costs for each hospital. These results can be used by managers to inspire innovative solutions for redesigning care processes and reimbursement strategies, better cost assessment, and to support cost-saving opportunities and value-oriented strategies in healthcare.

\section{Acknowledgments}

Funding: This study is a component of a larger Brazilian Ministry of Health project aimed at developing lines of research in health technology assessment for the Brazilian Unified Health System Institutional Development Program (PROADI-SUS) at Hospital Moinhos de Vento. 


\section{Footnote}

Data Sharing Statement: Available at https://jhmhp. amegroups.com/article/view/10.21037/jhmhp-21-34/dss

Peer Review File: Available at https://jhmhp.amegroups.com/ article/view/10.21037/jhmhp-21-34/prf

Conflicts of Interest: All authors have completed the ICMJE uniform disclosure form (available at https://jhmhp. amegroups.com/article/view/10.21037/jhmhp-21-34/coif). APBDSE and CAP receive payment or grant from Roche, BMS, HMV and HCOR. JADFN receives consulting fees from AMCA. The other authors have no conflicts of interest to declare.

Ethical Statement: The authors are accountable for all aspects of the work in ensuring that questions related to the accuracy or integrity of any part of the work are appropriately investigated and resolved. The study was conducted in accordance with the Declaration of Helsinki (as revised in 2013). The study was based on a perspective of the public hospitals that provide healthcare service to the public system and was approved by the ethical committee from the Hospital de Clínicas de Porto Alegre, project number CAAE: 71078617010015327. Approval was granted by all ethical committees of participating hospitals and informed consent was not required because we are not collecting or evaluating personal and individual information from patients or professionals.

Open Access Statement: This is an Open Access article distributed in accordance with the Creative Commons Attribution-NonCommercial-NoDerivs 4.0 International License (CC BY-NC-ND 4.0), which permits the noncommercial replication and distribution of the article with the strict proviso that no changes or edits are made and the original work is properly cited (including links to both the formal publication through the relevant DOI and the license). See: https://creativecommons.org/licenses/by-nc-nd/4.0/.

\section{References}

1. Kaplan RS, Porter ME. How to solve the cost crisis in health care. Harv Bus Rev 2011;89:46-52, 54, 56-61 passim.

2. Shrank WH, Rogstad TL, Parekh N. Waste in the US Health Care System: Estimated Costs and Potential for
Savings. JAMA 2019;322:1501-9.

3. Chatfield SC, Volpicelli FM, Adler NM, et al. Bending the cost curve: time series analysis of a value transformation programme at an academic medical centre. BMJ Qual Saf 2019;28:449-58.

4. Porter ME. What is value in health care? $\mathrm{N}$ Engl J Med 2010;363:2477-81.

5. French KE, Albright HW, Frenzel JC, et al. Measuring the value of process improvement initiatives in a preoperative assessment center using time-driven activity-based costing. Healthc (Amst) 2013;1:136-42.

6. Porter ME, Teisberg EO. Redefining health care: creating value-based competition on results. Harvard Business Press, 2006.

7. Nilsson K, Bååthe F, Erichsen Andersson A, et al. Valuebased healthcare as a trigger for improvement initiatives. Leadersh Health Serv (Bradf Engl) 2017;30:364-77.

8. Tsai MH, Porter JC, Adams DC. The Denominator in Value-Based Health Care: Porter's Hidden Costs. Anesth Analg 2018;127:317.

9. Kaplan RS. Improving value with TDABC. Healthc Financ Manage 2014;68:76-83.

10. Dafny LS, Lee TH. Health Care Needs Real Competition. Harv Bus Rev 2016. Available online: https://hbr. org/2016/12/health-care-needs-real-competition

11. Akhavan S, Ward L, Bozic KJ. Time-driven Activity-based Costing More Accurately Reflects Costs in Arthroplasty Surgery. Clin Orthop Relat Res 2016;474:8-15.

12. Etges APBDS, Ruschel KB, Polanczyk CA, et al. Advances in Value-Based Healthcare by the Application of TimeDriven Activity-Based Costing for Inpatient Management: A Systematic Review. Value Health 2020;23:812-23.

13. Sabharwal S, Carter AW, Rashid A, et al. Cost analysis of the surgical treatment of fractures of the proximal humerus: an evaluation of the determinants of cost and comparison of the institutional cost of treatment with the national tariff. Bone Joint J 2016;98-B:249-59.

14. Yu YR, Abbas PI, Smith CM, et al. Time-driven activitybased costing: A dynamic value assessment model in pediatric appendicitis. J Pediatr Surg 2017;52:1045-9.

15. Erhun F, Mistry B, Platchek T, et al. Time-driven activity-based costing of multivessel coronary artery bypass grafting across national boundaries to identify improvement opportunities: study protocol. BMJ Open 2015;5:e08765.

16. Merguerian PA, Grady R, Waldhausen J, et al. Optimizing value utilizing Toyota Kata methodology in a multidisciplinary clinic. J Pediatr Urol 2015;11:228.e1-6. 
17. Martin JA, Mayhew CR, Morris AJ, et al. Using TimeDriven Activity-Based Costing as a Key Component of the Value Platform: A Pilot Analysis of Colonoscopy, Aortic Valve Replacement and Carpal Tunnel Release Procedures. J Clin Med Res 2018;10:314-20.

18. Grocott MPW, Edwards M, Mythen MG, et al. Perioperative care pathways: re-engineering care to achieve the 'triple aim'. Anaesthesia 2019;74 Suppl 1:90-9.

19. Keel G, Savage C, Rafiq M, et al. Time-driven activitybased costing in health care: A systematic review of the literature. Health Policy 2017;121:755-63.

20. da Silva Etges APB, Cruz LN, Notti RK, Neyeloff JL, Schlatter RP, Astigarraga CC, et al. An 8-step framework for implementing time-driven activity-based costing in healthcare studies. The European Journal of Health Economics [Internet]. 2019 Jul 8 [cited 2019 Jul 11]; Available online: http://link.springer.com/10.1007/s10198019-01085-8

21. da Silva Etges APB, Polanczyk CA, Urman RD. A standardized framework to evaluate the quality of studies using TDABC in healthcare: The TDABC in Healthcare Consortium Consensus Statement 2020.

22. Organization for Economic Co-operation and Development (OECD). European Statistical Office (Eurostat). Eurostat-OECD methodological manual on purchasing power parities. Luxembourg: Publications Office of the European Union 2012. [Internet]. [cited 2020 Nov 11]. Available online: https://www.oecd.org/sdd/ prices-ppp/PPP\%20manual\%20revised\%202012.pdf

23. Mandigo M, O'Neill K, Mistry B, et al. A time-driven activity-based costing model to improve health-care resource use in Mirebalais, Haiti. Lancet 2015;385 Suppl

doi: $10.21037 /$ jhmhp-21-34

Cite this article as: Etges APBDS, Cruz LN, Schlatter RP, Neyeloff J, Ferranti E, Kopittke L, Nunes AA, Santos JSD, Ungari AQ, de Figueiredo Neto JA, Nogueira JL, de Assis RM, Moreira LB, Polanczyk CA. Identifying cost-saving opportunities for surgical care via multicenter time-driven activity-based costing (TDABC) analysis as exemplarily shown for cholecystectomy. J Hosp Manag Health Policy 2022;6:14.
2:S22.

24. Koehler DM, Balakrishnan R, Lawler EA, et al. Endoscopic Versus Open Carpal Tunnel Release: A Detailed Analysis Using Time-Driven Activity-Based Costing at an Academic Medical Center. J Hand Surg Am 2019;44:62.e1-9.

25. Nurok M, Warsh J, Dong E, et al. Achieving Value in Highly Complex Acute Care: Lessons from the Delivery of Extra Corporeal Life Support. :12.

26. Waters H, Abdallah H, Santillán D. Application of activitybased costing (ABC) for a Peruvian NGO healthcare provider. Int J Health Plann Manage 2001;16:3-18.

27. McLaughlin N, Burke MA, Setlur NP, et al. Time-driven activity-based costing: a driver for provider engagement in costing activities and redesign initiatives. Neurosurg Focus 2014;37:E3.

28. Beverly A, Vrochides D, Urman RD. Enhanced Recovery After Surgery: Evidence for Delivering Value-based Care. Int Anesthesiol Clin 2017;55:78-89.

29. Lemanu DP, Singh PP, Stowers MD, et al. A systematic review to assess cost effectiveness of enhanced recovery after surgery programmes in colorectal surgery. Colorectal Dis 2014; 16:338-46.

30. Stowers MDJ, Lemanu DP, Hill AG. Health economics in Enhanced Recovery After Surgery programs. Can J Anesth/J Can Anesth 2015;62:219-30.

31. Etges APBS, Stefani LPC, Vrochides D, et al. A Standardized Framework for Evaluating Surgical Enhanced Recovery Pathways: A Recommendations Statement from the TDABC in Health-care Consortium. JHEOR 2021;8:116-24. 
Supplementary

Table S1 Hospital characteristics

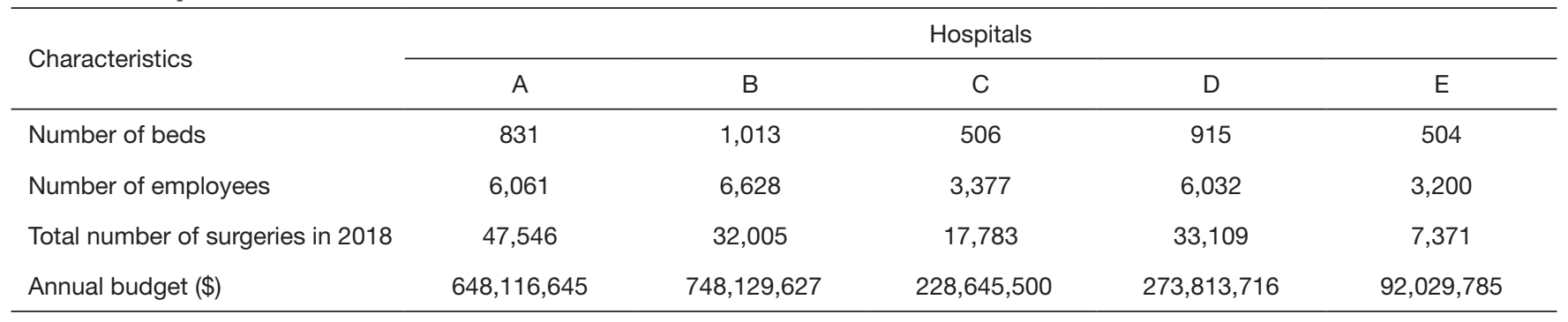

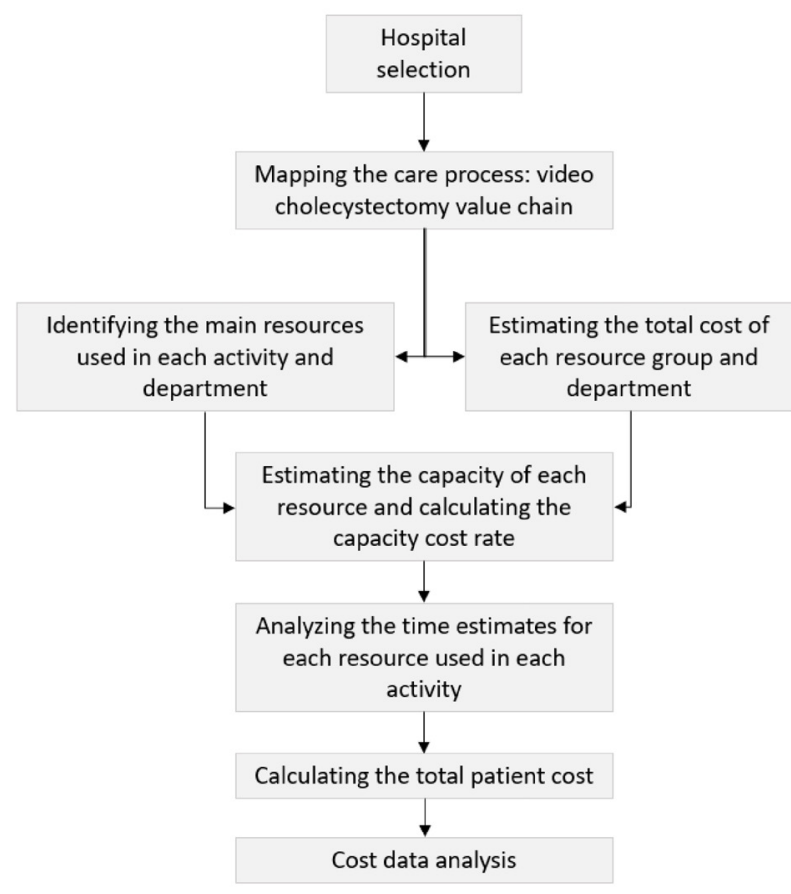

Figure S1 Application of the TDABC. TDABC, time-driven activity-based costing. 
Table S2 TDABC checklist

TDABC elements

1.1 It is defined if the results are being explored for general health service management or redesign and value or only to assess costs?

1.2 Is the clinical pathway, technology or procedure studied justified because of an interest from government, hospital, society or a Health Technology

1.3 Are study limitations being presented?

1.4 Is the TDABC method selection being justified?

2.1 Are authors using specific methodologies to design the care pathway?

2.2 Are authors using a multidisciplinary team to apply the TDABC? (Design the process, correctly consider clinical characteristics, correctly evaluate costs)

2.3 Are authors reporting activities in the process map on a macro level?

2.4 Are authors reporting activities in the process map on a micro level?

2.5 Is the full process map (or a part of being presented in a picture or graphic display?

3.1 Is a table or a map being presented to illustrate the association between activities and resources?

3.2 Are the resources that are included in the analysis being defined and justified?

3.3 Are authors reporting observation in-situ approach to better identify resources used in each activity?

3.4 Are the authors interviewing the professionals to better identify resources used in each activity?

4.1 When using hospital financial database, it is being stated how those data were collected and analyzed?

4.2 Are authors defining the currency and applying discount taxes when it is necessary?

4.3 When using external financial databases, is there a description of the database and how those data were accessed?

4.4 When mixed financial databases are being used (for example, salaries from external reference and structural costs from the hospital) is the origin of each

4.5 Did the authors explaining how the overhead costs are being considered?

5.1 Are authors defining if the capacity data used represents the total capacity per resource or it is being considered an expected idleness?

5.2 When authors are considering an expected idleness, it is explained how actual performance data were collected and analyzed?

6.1 Are authors explaining how time data were collected?

6.2 Are authors using interviews with professionals crossed with medical record review to estimate time data?

6.3 When using chronoanalysis, it is being explained how the sample of data was defined?

6.4 Is it being explained if the chronoanalysis used a digital technology to collect real time data, such as mobile app, wearable, drone, etc.?

7.1 Is the median or average cost per patient (or per technology) being calculated?

7.2 Are authors presenting the cost per each patient included in the sample? (Chart bar, table, etc.)?

7.3 Is the median or average cost per activity on a macro level being presented?

7.4 Is the median or average cost per activity on a micro level being presented?

7.5 Is the median or average cost per resource being presented?

7.6 Are authors performing capacity idleness analysis?

7.7 Are authors exploring statistical analyses to better understand costs along the process of care?

78 If the objective was to use the study to support management and value decisions, are authors reporting how value increasing was achieved or if they are planning to achieve it?

TDABC, time-driven activity-based costing.
Classification

Strongly Suggested, but not mandatory

Mandatory

Mandatory

Mandatory

Mandatory

Mandatory

Mandatory

Strongly Suggested, but not mandatory

Strongly Suggested, but not mandatory

Strongly Suggested, but not mandatory

Mandatory

Mandatory

Mandatory

Mandatory

Strongly Suggested, but not mandatory

Mandatory

Mandatory

Mandatory

Mandatory

Mandatory

Mandatory

Strongly Suggested, but not mandatory

Mandatory

Strongly Suggested, but not mandatory

Mandatory

Mandatory

Mandatory

Mandatory

Mandatory

Strongly Suggested, but not mandatory

Strongly Suggested, but not mandatory

Strongly Suggested, but not mandatory

Introduction

Introduction

Discussion

Introduction

Method

Methods

Methods

Methods

Results

Results

Methods

Results

Results

Methods

Methods

Methods

Methods

Methods

Methods

Methods

Methods

Methods

Methods

Result and

Discussion

Result and

Discussion

Result and

Discussion

Result and

Discussion

Result and

Discussion

Result and

Discussion

Result and

Discussion

Result and design and value

o, but in this case the clinical pathway was used an example to demonstrate No, but in case he cinical pa hay was wed an exampes. Hown

Ys, it is the aim of the study to demonstrate how the method can be used to guide redesign initiatives that can result in cost-savings Yes, explained in the methods

Yes, Table S2

No.

Yes, all structural and labor

Yes.

Sos, collected in Reais $(R \$)$ and reported in I\$

Yes, it was not included

was not being considered an expected idleness

observer followed by professionals interviews

No, it is not being used

Yes

Yes

No

Yes

No

Yes, possible cost savings 


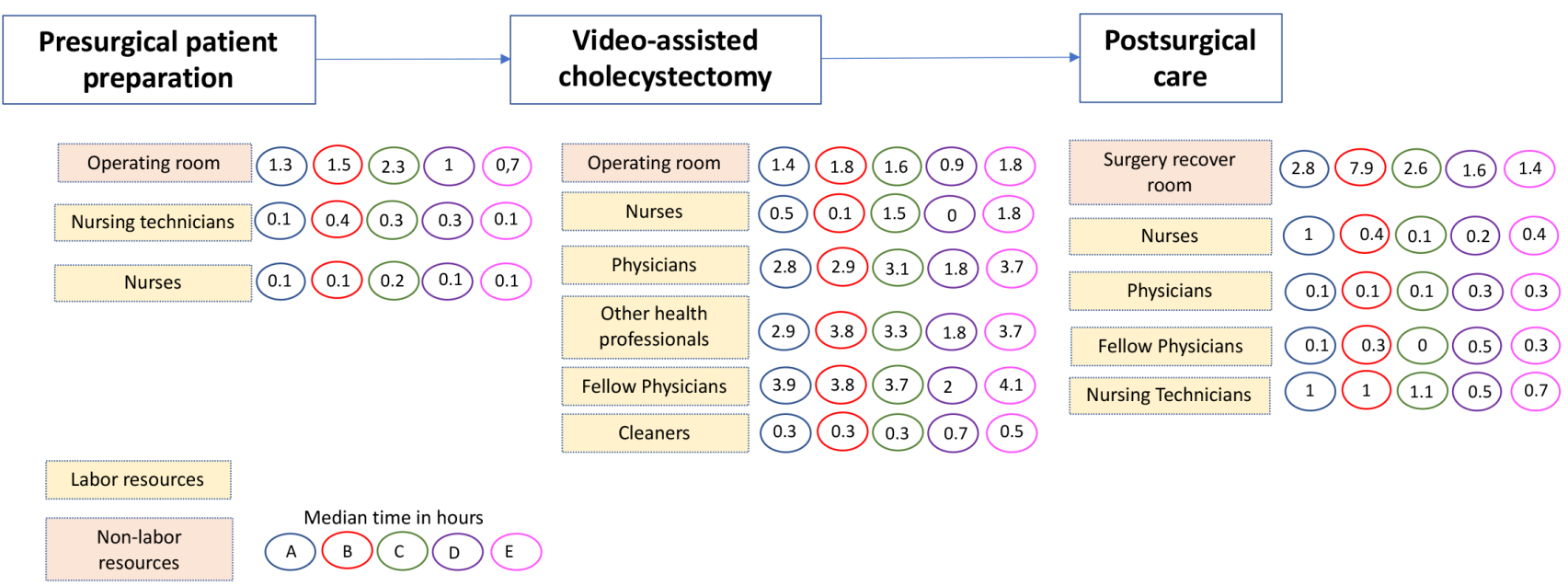

Figure S2 Surgical pathway cost variables. Stratification of the labor and non-labor cost variables along the tree macro phases of the surgical pathway. The colored circles indicate the median time in hours consumed by each resource in each hospital (A-blue, B-red, C-green, D-purple and E-pink). 